\title{
Locally led change and sustainability in Aotearoa, New Zealand
}

\author{
D. Bijoux \\ Inspiring Communities, Auckland, New Zealand
}

\begin{abstract}
Locally-led change and sustainability is gaining traction in Aotearoa New Zealand amongst community groups, local NGOs and central government because it leverages community resources in ways that grow resilience in communities and enables communities to be their best. It also ensures the relevance of resulting activities, along with enabling 'outside' resources to go further. However, by its very nature, locally-led action manifests in different ways in different places and at different times and this can make it difficult to understand and amplify/replicate.

This paper draws on practice-based evidence from nine communities across Aotearoa New Zealand that have helped refine core principles and practices of Community-led Development (CLD). Each of these communities has been consciously organising and working in community-led ways for a number of years and all agreed to contribute to a three year research project to better understand why this way of working was useful to them; what outcomes they were aiming for; how they were using community-led approaches; and what differences this way of working was actually making. The results reveal how working in such a way has contributed to sustaining what is valued by local people, and to inspiring and activating change that includes local voices at the decision making table as well as in the action taking phases. The paper provides a summary of these results as well as the key principles of locally-led change and sustainability as experienced in these initiatives. The paper concludes with some key actions that have contributed to success in these communities.

Keywords: locally-led change, Community-led Development, sustainability, community, neighbourhood, New Zealand, resilience, practice-based evidence, Inspiring Communities.
\end{abstract}




\section{Introduction}

Inspiring Communities was formed in 2008 to help support and strengthen the emerging Community-led Development (CLD) movement in Aotearoa New Zealand. CLD is about working together in strengths based ways 'in place', to create and achieve locally owned visions and goals [1]. This approach puts place in the centre (Figure 1) and recognises that both the opportunities and the challenges communities have are not likely to be maximised or solved by communities working alone.

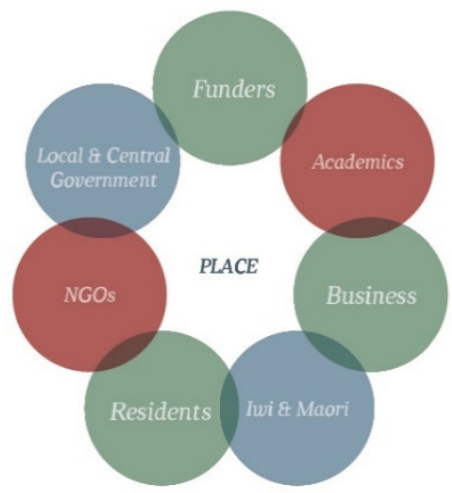

Figure 1: Place is at the centre of Community-led Development.

Also referred to as locally-led change and sustainability, CLD has multiple start points and looks different at different times and in different places. This is at least partly because it is of that place - it works with and builds on what people already have and leverages this with 'outside' resources. There are, however, some principles and approaches common to successful CLD. These have emerged from Inspiring Communities' work with a 'core learning cluster' of nine communities across the country to learn more about the practice and outcomes of CLD. The Core Learning Cluster (CLC) communities involved in this work included the island community of Rakiura (Stewart Island) in the far south, small towns in both the South and North Islands (Mataura, Waitara and Opotiki) and urban neighbourhoods in Wellington and Auckland (Taita, Porirua, Glen Innes, Massey and Ranui).

This paper summarises these findings with examples from several of the communities. It also offers some key principles of CLD that have been drawn from these findings as well as the key actions that have contributed to success for these communities. These have since been shared with many other communities who have, in turn adapted the approaches to grow both capacity and capability that strengthen wellbeing outcomes in their places too. 


\section{Methodology}

A multiple method approach was used so that both data collection methods and results could be woven into each project's development as the research progressed. These processes were focused on gathering information around four key questions:

1. What was the community change intended?

2. Why were community-led approaches used?

3. How were community-led approaches used?

4. What differences did working in CLD ways make?

These questions aimed to reveal key principles of CLD so that locally-led activities could be better understood and adapted elsewhere. The questions were answered using the four tools described below.

\subsection{Learning forums}

Learning forums, involving at least 2 members from each CLD initiative, were held twice during the study period to share key experiences, as well as to share lessons and to learn together. They provided an opportunity to infuse new international thinking including complexity thinking [2], success case method (Brinkerhoff [3]), quadrants of change [4], constellation governance [5], the ecocycle [6], developmental evaluation [7]. They were also used to clarify intent, and to ensure local tools and approaches were aligned to this intent [8]. They also allowed initiatives to share, refine and adapt methods used elsewhere for their own situations. Learning forum participants were surveyed immediately after the forum using survey monkey.

\subsection{Check-in calls}

These calls were designed to offer deliberate reflection space to a small group of people involved in the initiative, rather than one to one conversation with one key person. The calls overviewed what was working well, where challenges were and what opportunities these offered as well as what the most significant recent changes were. Data from calls was collated regularly and fed back to communities so they could 'hear' their own reflections and see the trajectories and patterns of their initiatives using relatively micro data. This was key in revealing how the various activities influenced one another, often in unexpected ways.

\subsection{Learning and outcome stories.}

Up to 10 learning and outcome stories were collected from each community. These stories were based on a framework adapted from work done in pre-school environments using a methodology designed by Margaret Carr [9]. These stories describe key successes as identified by those involved and highlight specific 
outcomes and learnings they see as important. This enables discussion of not only what was achieved but also how it happened, what factors local people suggest were critical to that success, along with what they would do differently next time.

\subsection{Periodic workshops}

Reflective practice workshops were held with each of the communities at least once. These workshops used tools developed in the learning forums as well as lessons outlined in Block [10], Diers [11], Born [12] and Gamble [13] to help guide project development while also assessing where and how various differences were being made.

As results were generated and collated, workshops also provided a space for collective analysis where local people discussed both their local and the overall findings in ways that enabled their understandings to drive the resulting meaning making, including distillation of key principles of CLD. This process also informed next steps planning.

\section{Summary of findings}

The core focus of Inspiring Communities' learning programme was understanding and communicating the difference that working in CLD ways has been making on local community journeys to achieve their goals. As Table 1 shows, these differences are many and varied. They range from engaging large numbers of people who would otherwise not have been involved in community projects, to seeding and contributing to other initiatives and playing formative roles in the development of groups that came together that most likely would not have if the CLC initiatives were not there.

Table 1: Aggregated totals of self-reported numbers from each CLC.

\begin{tabular}{|c|c|c|c|c|c|}
\hline $\mathbf{2 1 3 5 0 +}$ & $\mathbf{5 6 9 +}$ & $\mathbf{4 8 0 +}$ & $\mathbf{7 9 7 +}$ & $\begin{array}{c}\text { Ranges from } \\
\mathbf{1 0 0 s} \text { to 1000s }\end{array}$ & $\begin{array}{c}\text { Between } \\
\mathbf{\$ 2 0 -} \mathbf{\$ 3 0 /} \\
\mathbf{h o u r}\end{array}$ \\
\hline $\begin{array}{c}\text { Number of } \\
\text { local people } \\
\text { involved in CLC } \\
\text { initiatives }\end{array}$ & $\begin{array}{c}\text { Number of } \\
\text { other initiatives } \\
\text { CLC initiatives } \\
\text { have seeded }\end{array}$ & $\begin{array}{c}\text { Number of } \\
\text { initiatives CLC } \\
\text { initiatives have } \\
\text { contributed to }\end{array}$ & $\begin{array}{c}\text { Number of } \\
\text { alliances formed } \\
\text { through CLC } \\
\text { initiatives }\end{array}$ & $\begin{array}{c}\text { Number of } \\
\text { hours leveraged } \\
\text { through CLC CLD } \\
\text { from } \\
2010-12\end{array}$ & $\begin{array}{c}\text { Minimum } \\
\text { dollar value } \\
\text { of these } \\
\text { hours }\end{array}$ \\
\hline
\end{tabular}

What emerged from this research is that CLD makes an active and substantial contribution towards the ways in which people work as well as the outputs and outcomes they achieve together. These contributions to the ways in which people work vary over time and place, and are closely connected to why CLD approaches were chosen. This also means that those involved often understand the differences their work together contributes to as a mix of process and people outcomes. 


\subsection{What was the community change intended?}

Motivation to work in ways where communities are leaders of the changes they want to see in their communities comes from a range of sources and is contextual. Most commonly, motivations focus on wanting to make a place "better" than it is currently and/or in response to a particular issue, concern or perceived threat.

Within the CLC, these motivations arose from combinations of factors that include concerns about health, debt, land grievances, unemployment, low economic growth and crime. Energy on Rakiura was, for example, focused on sustaining the unique local natural environment in the face of changing demographics and economics, and helping all of these to work together. In Mataura and Waitara the focus was on small town revitalisation, but coming from quite different backgrounds and current situations. In Opotiki, the redevelopment of the harbour offered a unique opportunity to re-grow indigenous connections, partnerships and economic development. The opportunities in the cities also varied. In Porirua, arresting the spiral of debt that many people found themselves entangled in was a priority; in Taita the focus was on the improved wellbeing of children and families; Glen Innes wanted to make sure local voices were included in the major government-led urban transformation project taking place there; and Massey and Ranui were focused more on neighbourhood-led development and community cohesion.

The kinds of community changes intended thus varied but, while the focus for change or sustainability in each place was quite different, the common starting point was that local people were organising in various ways to contribute to the (re)creation of local places as they wanted them to be. Local people were (and are) part of the decision making processes as much as of the action taking phases. This is a critical point because it meant that local people's aspirations were directly reflected in direction setting rather than being engaged in or consulted about visions and directions developed by others. These aspirations included relatively small and tangible changes such as using a building in different ways, or developing a community garden, to much more ambitious, and not always tangible, shifts such as developing industries, improving social and cultural wellbeing, increasing quality of life and better coordinating current visions, energies and use of resources.

In fact, in all of the CLC communities, multiple changes were intended. For example, in Waitara improving town pride sat alongside developing a more resilient economic base [14] while on Rakiura developing an overarching vision for the island so that existing community efforts could be better aligned was as important as the focus on environmental conservation and ecotourism [15].

Furthermore, in many cases, sustaining what was already valued locally was a key part of the mix and improving sustainability, whether that be environmental, economic or socio-cultural was also often an underlying theme. 


\subsection{Why were CLD approaches used?}

Although specific motivations varied, in their own ways each of the CLC initiatives included key individuals who recognised that local change and sustainability is more relevant and appropriate when it includes, and is guided by, local expertise that comes from local lived experience. These individuals understood, often from previous experience, that local experience can be invaluable to the successful harnessing and use of outside resources. They also realised that their places were not without assets or aspirations, and including local voices in project development from the very beginning can help outside resources be used in ways that are most relevant and effective. In other words, there was a degree of competency, capacity and capability amongst key individuals in these communities in terms of including local voices and enabling and empowering local communities to respond to particular situations and opportunities.

For these key local people, sustaining local values and/or achieving the changes local people wanted to see often meant starting by working out overarching goals and aspirations that were derived from local people collectively. In Taita, for example, Great Start knocked on over 1200 local doors, while in Massey, Mataura and Rakiura community visioning sessions were held, and in Opotiki new partnerships focused on shared aspirations between local government and local tribes came about after many, many hours of talking and exploring together.

In different ways in each of the communities, this process revealed very quickly that local people wanted to be involved in achieving local dreams, goals and actions too. Moreover, many of the people involved also realised that by combining existing skills, resources and talents in different ways, they were more able to influence local futures.

Being lightly connected by an overall vision or goal that was jointly led and held by those participating allowed for variation in activities to achieve the vision or goal as much as it encouraged a common focus. Getting to a position of understanding not only why people want to work together but also how what they already have that can contribute to the achievement of that goal, aspiration or dream meant communities (not just residents but including people who live, work, play, invest and care for a place) were already in the driving seat. This is a significant precursor to success of locally-led action as, most commonly, communities are encouraged to amplify their deficits rather than their assets in order to achieve profile and extra resources.

Continuing to take a CLD approach also meant that not only was there potentially something for everyone to be involved in, but if one particular activity fell over, others could continue to contribute to the overarching goals in their own way. Such an approach helped enable things to get done in a nimble, high impact manner by letting people get on and do what they do best, using the skills, talents and resources they already had. The attraction of working in locally-led ways was, then, as much practical as it was philosophical. 
For the organisations involved - local government, central government, iwi, NGOs and community groups - working in CLD ways was seen as assisting their investment and resources more efficiently and in ways that were more relevant and appropriate to the local community. In addition, because each organisation was part of a wider group, risks were shared and investments from individual organisations optimised.

For some initiatives, such as Great Start in Taita (which was at the time, a part of Barnardos, a national child focused social service organisation,) this meant a significant shift in practice from being a provider of services to becoming 'of service' to and with local people. In Great Start's case, door knocking revealed what local people wanted more of in their community and Great Start set out to use their existing resources to assist local people to achieve the things they had identified. In some cases that meant bringing service providers to deliver from the Great Start house in Taita, but in others it meant assisting local people to work to their strengths themselves [16].

Working in CLD ways thus helped to generate approaches that were more flexible to changing local conditions and also often yielded wider than expected results too. Over time these results have both attracted more interest in the initiatives, which helped to sustain them, and also encouraged people in other organisations and places to work in locally-led ways too.

Two fabulous examples of this with regard to Great Start are:

1. The Common Unity Project working with Epuni School in Wellington developed from experience at Great Start. Their initial focus on a large community garden on the school site has since grown to become a part of the school curriculum, as well as expanding to include a koha kitchen, bike library, sewing and knitting groups. All of this achieved through using existing community resources and without a single grant application [17].

2. How Hutt City Council worked with local children to first commit resources to developing a new park and then working with those same children to design it. An initial group of children participated in a formal submission process in Council chambers and since then, other children's groups have been involved in various aspects of designing, building and using the park [18].

\subsection{How were CLD approaches used?}

Each initiative developed different structures to manage their development, including how CLD approaches were used. To begin progress towards collective visions, a projects approach was frequently favoured. In some cases one project became the core business of the initiative. For example, Good Cents Porirua arose out of a community-led learning inquiry, creating an innovative debt management and learning course as an entry point into the complex systems of indebtedness. This course has become the key project for the Good Cents initiative and it has evolved to include graduates as course facilitators. Course content and delivery methods have also evolved, drawing on other local skills 
such as those of bankers, lenders and community leaders. Learning more about the process of community-led change has also strategically influenced the host organisation, Wesley Community Action. The previous food bank at their Cannons Creek site, now transformed into a community pantry, with all available land on site turned into demonstration gardens. Around 80 back yard gardens are now being supported and a local food co-op recently established and thriving.

Shorter term projects made it easy for local people to join in, and being part of something successful led onto questions of 'what will we do next'. In Massey such a project was Te Raa Mokopuna - a free, fun day out in a local park to celebrate Massey's children, youth and families. Collaboratively organised by local organisations and local as residents, it filled the gap of 'no local flagship events'. The third annual event was held in March 2009 with around 2000 locals attending. Since then the event has been substituted by 'Our Amazing Place' community treasure hunt event which continues to be held annually and attracted 99 teams in 2014 [19]. Community-led approaches through projects in Massey were also encouraged through establishment of a small projects fund which enabled 100 new projects in its first three years. Local awards for individuals and organisations who demonstrated caring behaviour and leadership within Massey (Massey Marvels) were also celebrated.

Across all of the CLC, their most successful CLD approaches often started with relatively small projects that involved several people working together in visible ways. Such projects could often be designed around what a community already had, and so could get started quickly. These projects built on local strengths and assets, tapped into existing resources and developed stronger local connections by assisting and incentivising a variety of local actions while energy for the project was fresh. By choosing projects with highly tangible results, locally-led action became more visible in the community without necessarily being named as such, and the initiative itself was seen to 'add value'. This tended to mean that the initial project expanded in focus as did those wanting to be involved.

This was the case in Mataura (population 1500) where a few people had energy for a community garden to help local families but had been unable to get it off the ground. With the establishment of the Mataura Taskforce, which emerged as a collective "can-do" community response to a concerning report on the health of local people, a local man donated use of some land for the garden. A year later, the garden was so successful that it had raised enough money to buy the land, build a shed and tunnel house. The local Council and local businesses have donated time, goods and funds and, with the help of the 40 or so local people volunteering regularly, the garden now hosts the 'Green Fingers Club' with the local school and marae, and has also taken over local provision of the local Meals on Wheels which delivers meals to older people living in Mataura [20].

CLD has also been fostered by actively creating space for both leaders and 'joiners' both within and beyond local projects. Leaders are key to generating enthusiasm about the wider CLD initiative and movement, and make it less risky for others to join in by standing up and identifying an opportunity, then 
embracing joiners as equals. Those who join with leaders create momentum by demonstrating what working together can create and often become leaders themselves, especially when leading is understood as being "leaderful" [21].

CLD is actively cultivated through a leaderful approach because being leaderful is where leading can be done by more than one person at a time and so be collective. A leaderful community is also collaborative, so people can work to their strengths and in compassionate ways. Joiners do not need to become leaders to contribute however, and a CLD contribution may be in the form of navigation, coordination and convening or actively participating in projects. These roles are important to CLD because they bring different parties together to catalyse shared interests and activities, build on local values and assets, and grow community capacities, capabilities and readiness.

For example, the Back2Back project in Ranui undertook various roles including those of broker, supporter, initiator and ally to develop community-led relationships between residents, local and citywide organisations, government agencies and local authorities. This, in turn, supported residents and organisations to develop new ways of working with one another such as when Back2Back supported 60 residents to take action over vandalism and graffiti at the playground in their local park. Neighbourhood Support helped these local people develop a petition to Council Local residents then went on to plan further actions to develop their neighbourhood, including a community garden. Neighbourhood Support, Safe Waitakere, Sport Waitakere, Tag Out Trust, EcoMatters and the Police have all collaborated to support on-going initiatives in this neighbourhood since. In these ways, those that see value in working in community-led ways became the new leaders of it, taking the practice into different spaces [22].

\subsection{What differences did working in CLD ways make?}

The CLC initiatives clearly identified that the changes and outcomes they were most proud of were a combination of 'what' they achieved, as well as 'how' they worked towards the achievement, and 'who' they worked together with. 'What' projects were undertaken frequently changed to reflect the capacities and capabilities that CLD ways of working revealed in local people. That is, local initiatives tended to develop along the lines of the particular skills, inclinations and opportunities that were available locally, or within easy reach. In fact, one thing led to another in most of the CLC initiatives and this iterative, responsive and evolving approach was often how the initiatives were most effective.

Over the research period, the CLC initiatives reported focusing their efforts on a wide range of activities, achieving an equally wide range of changes. These changes included:

- $\quad$ increases in the school roll and an upgraded swimming pool on Rakiura;

- a community newsletter, community market, large scale community garden, youth centre, festivals and more in Mataura; 
- the Good Cents course, community pantry, joining up of different churches in conversation about debt and wealth and personal successes in Porirua;

- a tool library, toy library, children's gardening club, women's sewing and friendship group, time bank and more in Taita;

- economic development, increased road safety, neighbourhood connections, the beginnings of a new multi-sport facility and reduced crime in Waitara;

- youth-led murals, a cycleway, commercial mussel trials, improved participation in local planning and increased understandings of social, cultural and environmental sustainability in Opotiki;

- the development of the Music and Arts Glen Innes Centre, Tamaki Inclusive Engagement Strategy and book, Tamaki Community Action Research project, Manaiakalani and Healthy Relationships in Tamaki (HEART) amongst other things in Glen Innes and Tamaki;

- $\quad$ an annual community/family fun event (Te Raa Mokopuna), community network, community hub development, newsletter, enterprising communities project, school based community events, resident leadership workshops, clean-up days, neighbourhood resources for schools and communities, a new pedestrian bridge, school holiday initiatives and Massey Matters Fund in Massey and Ranui.

This wide range of changes also reflects the sustaining of local values and it highlights the role working in CLD ways can have with regard to both change and sustainability of hard and soft community assets. For the CLC initiatives, taking a projects approach helped to address the 'What's in it for me' factor at the same time as building social capital and growing a more collective 'civic' consciousness and experience. As well as yielding direct benefits, the projects approach also helped grow a CLD constituency and, after doing small projects, some people were naturally drawn into bigger picture community thinking and visioning.

Working in CLD ways tended to be most effective at the scale of lived experience: the smaller town, suburb or neighbourhood level. It was at these community scales that the strengths and assets of a community were best mobilised and synergised by people from within that community. Also at these scales, outcomes were most noticeable for local people. Experiences and learnings at these scales did lead to changes at other scales too however, including at the personal, group, organisational or wider system level.

For example, some philanthropic funders have made changes to the way they support local initiatives and CLD is noted in the Auckland Plan [23], the key visioning and strategic document developed by Auckland Council. Numerous other local authorities have adopted ways of funding locally-led activities and CLD is also an emerging platform that central government agencies are now more actively exploring.

More generally, CLD approaches are increasingly recognised to grow capacity and capability to achieve locally-defined aspirations in ways that enable 
local people to both lead and join in empowering ways. This often generates new ways of working across sectors, organisations and individuals that increases local ownership of change and addresses opportunities and issues in new and creative ways. Growing multiple leaders is also recognised to help build local resilience and underlies the relevance, sustainability and longevity of initiatives because it encourages flexibility and working with multiple strengths within a core common purpose. Achieving this is often seen as an outcome in itself.

\section{Discussion}

Because working in CLD ways necessarily involves working with what is already there in each community and building on local strengths, assets and resources, extracting CLD's contribution to change can be difficult. Results from the CLC initiatives show that CLD makes an active and substantial contribution towards the ways in which people work together, as well as the outputs and outcomes they achieve together. These results show that CLD is a key contributing factor to both sustaining what is already valued and in contributing to visible change in communities; concurrently transforming relationships, culture and structures as alongside achieving project goals. It also highlights the presence, across all nine initiatives, of five core principles. These are:

1. Planning and action that's driven by local visions;

2. Local people leading in strengths based ways;

3. Many sectors working together to unlock creativity and resources;

4. Intentionally growing local leadership capacity; and

5. Concurrent and adaptive planning, action and reflection of outcomes against intent.

These principles express how working in CLD ways is inherently intentional, collaborative and strengths based, with the aim of building on what is already present. CLD encourages using existing resources differently and attracting new resources where that is useful. It is also about securing new ways of resourcing and developing new kinds of partnerships as well as ensuring there is regular reflection and review of progress against intended outcomes.

As well as co-creating local change, CLD is also about systems change and often makes deliberate efforts to advocate for more appropriate support from various 'systems', such as policy, practice and funding from within local government for example. With this in mind, the CLC came to recognise that working in CLD ways was an outcome in and of itself because working in CLD ways often represents a significant change from previous efforts to achieve local change. Working in CLD ways requires a change of behaviour, where 'bottom up' visions and priorities meet those from the 'top down' and this requires a change in behaviour, expectations and roles for both organisations and local people. CLD ways of working have, therefore come to be seen as outcomes of the process ('practice outcomes'), and these practice outcomes are just as important for the local resilience and sustainability as the progress and people outcomes achieved. 
Practice outcomes are related to how CLD approaches operate and they often directly lead onto other tangible outcomes as well, largely because of why people come together, who is involved and what roles they are enabled to play Because CLD puts place at the centre, the inclusion of communities and groups who may otherwise have had a limited involvement or been excluded altogether encourages behaviour changes amongst all parties and it is important to acknowledge and document these so CLD practice can continue to evolve.

In terms of practice, the key actions that have contributed to success for these communities are:

- Starting with conversations

- Growing relationships

- Being intentional

- Building on assets and strengths

- Creating something visible

- Doing it together with others

- Mapping your contribution to change

- Doing no harm, having fun and striving for results!

\section{Conclusions}

Locally-led approaches to change and sustainability are being applied across Aotearoa New Zealand to enable and support more relevant and appropriate local development that is, in turn, growing local resilience. These approaches are being adopted, adapted and applied by local people as well as by various organisations including community groups, NGOs, local and central government because CLD approaches leverage community resources in ways that enable organisational and resources from outside local places to go further.

The impact of CLD is part of both how and what is achieved by these partnerships. CLD is a way of working that contributes to outcomes because of who is involved, how they are involved, what they do and how well they do it. The benefits of working in CLD ways are personal, relational, structural and cultural as much as they are also often tangible in terms of project deliverables. This wide range of benefits can be difficult to measure and, recognising that CLD is only a part of the equation, proponents of CLD do not seek to determine attribution. What is important, however, is making the role of CLD more visible so it can be better understood and, through this research, that has been most effectively communicated through practical examples and stories from applying the core CLD principles.

\section{References}

[1] Inspiring Communities. Learning by Doing, 2013.

[2] Westley, F., Zimmerman, B. and Quinn Patton, M. Getting to Maybe. 2006. 
[3] Brinkerhoff, R. The Success Case Method: Find out quickly what's working and what's not. 2002.

[4] Lederach, J., Neufeldt, R. and Culbertson, H. Reflective Peacebuilding: A planning, monitoring and learning toolkit. 2007.

[5] Surman, T. and Surman, M. Listening to the Stars: The constellation model of collaborative social change (2008).

[6] Cabaj, M. Collaboration, Renewal or Winddown? 2010. tamarackcommunity.ca/.../CCI_downloads/CCI2010_MCabaj_Sustain.pdf

[7] Quinn Patton, M. Developmental Evaluation. 2011.

[8] Inspiring Communities. What we are Learning about Community-Led Development. 2010, pages 37-47.

[9] Carr, M. An Assessment in Early Childhood Settings: Learning Stories. 2001.

[10] Block, P. The Answer to How is Yes: Acting on what matters. 2002.

[11] Diers, J. Neighbor Power: Building Community the Seattle Way. 2004.

[12] Born, P. Community Conversations. 2008.

[13] Gamble, J. Evaluating Vibrant Communities Canada: 2002-2010. 2010.

[14] Willis, M and Bijoux, D. Waitara Community Development Project: Growing what Waitara wants. 2012.

[15] Beaven, K and Beaven B. Stewart Island "Snack and Yak" The connecting space between local community-led projects. 2011.

[16] Grenfell, K and Bijoux, D. One Tuesday Afternoon: Sewing, cooking and learning together to make 'home' in a new land. 2012.

[17] Common Unity Project http://commonunityproject.org.nz/index.html 2012.

[18] Bijoux, D, Strange, L and Rei, S. Partnering with Children: My story. 2011.

[19] Anonymous. Our Amazing Place, Massey, Treasure Hunt and Picnic http://www.ourwest.co.nz/2014/05/12/amazing-place-massey-treasurehunt-picnic/ 2014.

[20] Brand, J. and Bijoux, D. Gaining a Reputation: Mataura Community Garden. 2012.

[21] Raelin, J. A. The Leaderful Fieldbook: Strategies and activities for developing leadership in everyone.

[22] Chilcott, J and Bijoux, D. Getting started with street-level engagement and neighbourhood-led development: a synopsis of the Back2Back experience. 2012.

[23] Auckland Council, The Auckland Plan, 2012. 